\title{
TELECOM INDUSTRY BEFORE AND AFTER RELIANCE JIO
}

\author{
Sonu Daniel Sam ${ }^{1}$, Prof. Sneha Kanade ${ }^{2}$ \\ ${ }^{1}$ MBA, Garden City University, Bangalore \\ ${ }^{2}$ Assistant Professor, School of Commerce and Management, Garden City University, Bangalore \\ DOI: 10.46609/IJSSER.2021.v06i04.007 URL: https://doi.org/10.46609/IJSSER.2021.v06i04.007
}

\begin{abstract}
Reliance Jio is the game changer in the mobile data industry. The company was able to acquire sizeable market share in a short span of time. The study focuses on the changes that Reliance jio introduced in the telecom industry. The end of 2016 saw major reforms in the nation's telecom sector when Reliance Jio entered the Indian telecom scene as a new service provider wherein all the existing service providers were taken for a ride by Jio's aggressive strategies in pricing, service offerings and the rise of customer curiosity and thereby subscribers choosing or porting their existing numbers to Jio. The study explores the changes introduced in the telecom company.
\end{abstract}

Keywords: telecom industry, pricing strategy, customer curiosity, Reliance Jio.

\section{Introduction}

India's telecommunication network ranks second in the world by the number of telephone users (both fixed line and mobile phone) with 1,171.80 million subscribers as on 31 October 2020. It has one of the lowest call tariffs in the world enabled by mega telecom operators and the hyper-competition among them. The competition and price wars among the players in the telecom industry are monitored closely and regulated thoroughly by the Telecom Regulatory Authority of India (TRAI), a statutory body setup by the Government of India.

The end of 2016 saw major reforms in the nation's telecom sector when Reliance Jio entered the Indian telecom sceneas a new service provider wherein all the existing service providers were taken for a ride by Jio's aggressive strategies in pricing, service offerings and the rise of customer curiosity and thereby subscribers choosing or porting their existing numbers to Jio.

This project studies on how the entry of Reliance Jio evolved the then Indian telecom sector to what we see today, by analyzing the revenues, subscriber turnover rates and other factors that affect the day to day functioning of the industry by comparing certain major players in the industry; thestate-owned Bharat Sanchar Nigam Limited (BSNL), Airtel, Vi (previously 
International Journal of Social Science and Economic Research

ISSN: 2455-8834

Volume:06, Issue:04 "April 2021"

independent entities named Vodafone India and Idea Cellular Limited)with Reliance Jio Infocomm Limited (Reliance Jio), a subsidiary of Reliance Industries led by Mukesh Ambani.

\section{Review}

\section{Arpit Srivastava - Effect of Jio on Indian Telecom Industry Landscape}

This article probed into the introduction of Reliance Jio and how its entry has disrupted the existing scenario in the nation. It studied the impacts the industry faced such as how revenues of competitors have shattered, how the existing voice and data plans were overturned, the narrowing of margins and how the pioneers existent in the industry faced the turmoil caused while having the burden of heavy license fees piled up on one hand. It also highlights the exorbitant rise of the country's internet usage; from 200 million GB a month to 1.5 billion GB a month, thereby making India the world's largest consumer of data. The study also spans through the introduction of Jio's LYF smartphones, a low cost 4G feature phone for the rural mass of the country. ${ }^{1}$

\section{Devina Gupta - Jio Effect: 5 Reasons Why Indian Telecom Industry Will Never Be Same Again}

The article studies about the impact that Jio has made and comments on the impact it has created on other telecom operators who is struggling to survive the phase, having to suffer falling revenues, rising cost of operations. The article also talks through the takeover of Telenor by Airtel to synergize its operations in new cities. It also cites that Reliance Jio is the sole reason for the Vodafone-Idea merger in 2018. The aggressive strategies by Jio have made its subscribers and the general public believe to an extend that the customer is still the 'King of the market' by offering a year's subscription for only ₹303, thereby forcing other service providers to reduce their existing exorbitant pricesbut failing at it miserably as Jio always had more offers under their sleeves to offer their subscribers. ${ }^{2}$

\section{Oxford Analytica Ltd., India}

The telecom market faces a massive shakeout.The entry of Reliance Jioshook the telecom sector in India. Many leading providers such as Airtel, Vodafone and Idea Cellular Limited experienced an immediate decline in their market value after Jio announced its plans to enter the market with their attractive offerings to their subscribers. This further fueled the market disruption as among the offers included, there were free voice calling and free data services for life for early subscribers. This strategy showed the results Jio wished for. They attracted millions of customers in a month after commencing operations. ${ }^{3}$ 
International Journal of Social Science and Economic Research

ISSN: 2455-8834

Volume:06, Issue:04 "April 2021"

\section{Akshat Chandergupta, ET Bureau - Jio's entry led to $\$ 10$ billion annual savings for India}

This article talks about the entry of Jio in September 2016 leading to $\$ 10$ billion in annual savings for India and a surge in the total data consumption of the country. Jio with the introduction of its offers have made it affordable even for a layman with meagre livelihood circumstances and income to access data at world class speeds, make calls with state of art highdefinition voice facilities with rates from ₹10 - ₹152, thus giving access to a much larger to population. It also highlights an interesting fact that India became the largest consumer of mobile data in the world within 6 months of Jio's commencement of operations in the country. With an estimate that every consumer uses $1 \mathrm{~GB}$ a month, the gains to the economy can be calculated with the benefit to all the 350 million internet subscribers, Jio will aid in expanding India per capita GDP by about $5.65 \%$, if everything else is constant in the economy. Jio has completely changed the entire competition scenario of the Indian telecom industry. ${ }^{4}$

\section{NoorulHaq - SWOT analysis of Reliance Jio}

Reliance Jio Infocomm Limited headquartered in Navi Mumbai, Maharashtra offers wireless 4G network services and held the credit of the only VoLTE (Voice Over LTE) operator in the country when it entered the market. Jio helms the credit of the best customer acquisition strategy till date. Within its first 170 days of operation, over 100 million subscribers registered themselves with Jio, making them India's largest internet provider. Reliance Jio holds a considerable presence in all 22 telecom circles in India. Having all the aforesaid strengths and opportunities, Jio also faced challenges, threats and weaknesses which in certain aspects are unique in the industry such as voice call failures among other operators, decreased internet speeds from 50 Mbps at the launch to 6-10 Mbps or even lower due to the increased growth in spread of customers, buggy Jio apps which comes bundled along after the SIM card is activated, lack of VoLTE support on older phones wherein Jio SIM cards require 4G LTE connectivity to make and answer calls. People who do not have phones with $4 \mathrm{G}$ connectivity has no benefit having a Jio SIM. ${ }^{5}$

\section{Objectives}

1. To study the impact of Reliance Jio on the telecom industry, the evolution of the Indian telecom sector after Reliance Jio's entry.

2. To identify the impact of Jioon common people and the effect on consumer behaviour.

3. To compare the financial and non-financial aspects of major players in the industry and the impact of Reliance Jio on those aspects after their entry to the industry. 
International Journal of Social Science and Economic Research

ISSN: 2455-8834

Volume:06, Issue:04 "April 2021"

\section{Methodology}

\section{Secondary data}

Most of the data collected for the project are from various published sources such as articles, findings and case studies to learn about the impact of Reliance Jio on the telecom industry, which is not possible to collect through primary research due to limitation of time and resource scarcity. The data collected are government data published by TRAI (Telecom Regulatory Authority of India) and also published research papers, articles from online news portals and case studies available online.

\section{Results}

Reliance Jio Infocomm Limited, or just Jio, is an Indian telecommunications company and a subsidiary of Jio Platforms under the Reliance Industries, headquartered in Mumbai, Maharashtra, India. It operates a nationwide LTE network with coverage across all 22 telecom circles. It doesn't offer $2 \mathrm{G}$ or $3 \mathrm{G}$ service, and instead uses only VoLTE (voice over LTE) to supply voice service on its $4 \mathrm{G}$ network.

Jio had a soft launch on 27 December 2015 with a beta for partners and employees, and became publicly available on 5 September 2016. At present, Jio is the largest mobile network operator in India and the third largest mobile network operator within the world with over 41.08 crore (410.8 million) subscribers.

In September 2019, Jio launched a fiber to the home service, named JioFiberoffering home broadband, television, and telephone services. Since April 2020, Reliance Industries has raised ₹ 152,056 crore (US $\$ 21$ billion) by selling $32.97 \%$ equity stake in Jio Platforms. ${ }^{6}$

\section{Service Provider wise Growth/ Decline in Subscriber base}

\begin{tabular}{|c|c|c|c|c|c|c|}
\hline \multirow{2}{*}{$\begin{array}{c}\text { Service } \\
\text { Provider }\end{array}$} & \multicolumn{3}{|c|}{ Subscriber base (millions) } & \multirow{2}{*}{$\begin{array}{c}\text { Rate of } \\
\text { growth } \\
(\%)\end{array}$} & \multirow{2}{*}{$\begin{array}{c}\text { Market } \\
\text { share in QE } \\
\text { Jun-20 (\%) }\end{array}$} & \multirow{2}{*}{$\begin{array}{c}\text { Market } \\
\text { share in } \\
\text { QE Sep-20 } \\
(\%)\end{array}$} \\
\hline & Jun-20 & Sep-20 & $\begin{array}{c}\text { Net } \\
\text { additions }\end{array}$ & & & \\
\hline Bharti Airtel & 320.94 & 331.03 & 10.08 & 3.14 & 27.66 & 28.33 \\
\hline Reliance Jio & 398.70 & 406.21 & 7.50 & 1.88 & 34.36 & 34.76 \\
\hline Vi & 305.56 & 296.00 & -9.56 & -3.13 & 26.33 & 25.33 \\
\hline BSNL & 126.48 & 126.73 & 0.25 & 0.20 & 10.90 & 10.84 \\
\hline
\end{tabular}


International Journal of Social Science and Economic Research

ISSN: 2455-8834

Volume:06, Issue:04 "April 2021"

\begin{tabular}{|l|c|c|c|c|c|c|}
\hline TOTAL & $1,151.68$ & $1,159.97$ & 8.27 & 2.09 & 99.25 & 99.26 \\
\hline
\end{tabular}

(Source:The Indian Telecom Services Performance Indicators, July-September '20,TRAI) ${ }^{7}$

- $M /$ s Bharti Airtel Ltd has reported the wireless subscribers including the subscribers of $M / s$ Tata Teleservices Ltd.

- $M / s$ BSNL includes number of subscribers of its Virtual Network Operator (VNO)

$\mathrm{M} / \mathrm{s}$ Reliance Jio Infocomm Ltd is the market leader with $34.76 \%$ in the access segment in terms of number of subscribers with 406.21 million subscribers at the end of Sep-20 followed by M/s Bharti Airtel Ltd with 331.03 million subscribers.

In term of net addition, Bharti Airtel Ltd. became the biggest gainer with net addition of 10.08 million telephone subscribers during the QE Sep-20.

\section{Access Services - Service Provider wise Adjusted Gross Revenue}

\begin{tabular}{|c|c|c|c|}
\hline Service Provider & $\begin{array}{c}\text { QE Sep-20 } \\
\text { (₹ in crores) }\end{array}$ & $\begin{array}{c}\text { QE Jun-20 } \\
\text { (₹ in crores) }\end{array}$ & \% change \\
\hline Reliance Jio & $15,915.14$ & $15,259.91$ & 4.29 \\
\hline Bharti Airtel & $10,764.90$ & $10,088.46$ & 6.71 \\
\hline Vi & $6,435.79$ & $5,865.36$ & 9.73 \\
\hline BSNL & $2,185.39$ & $2,140.40$ & 2.10 \\
\hline Grand Total (Access) & $\mathbf{3 5 , 3 0 1 . 2 2}$ & $\mathbf{3 3 , 3 4 5 . 1 3}$ & $\mathbf{5 . 8 6}$ \\
\hline
\end{tabular}

(Source:The Indian Telecom Services Performance Indicators, July-September '20, TRAI) ${ }^{8}$

3. Market shares of major telecom providers - Before \& After Jio entry

Graph 1: Pre-Jio; Market share of telecom providers 
International Journal of Social Science and Economic Research

ISSN: 2455-8834

Volume:06, Issue:04 "April 2021"

\section{Pre-Jio}

India had more than 10 mobile carriers when Jio entered the market in 2016

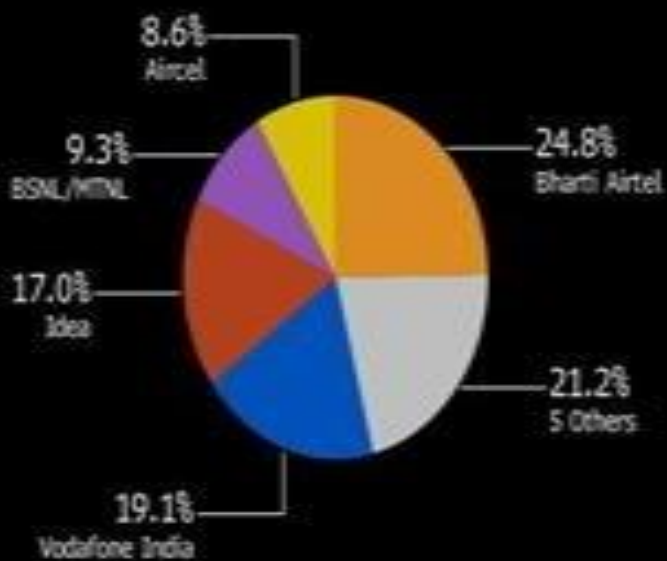

Graph 2: Post Jio; Market share of telecom providers

\section{Post-Jio}

Three dominant players now control India's wireless market

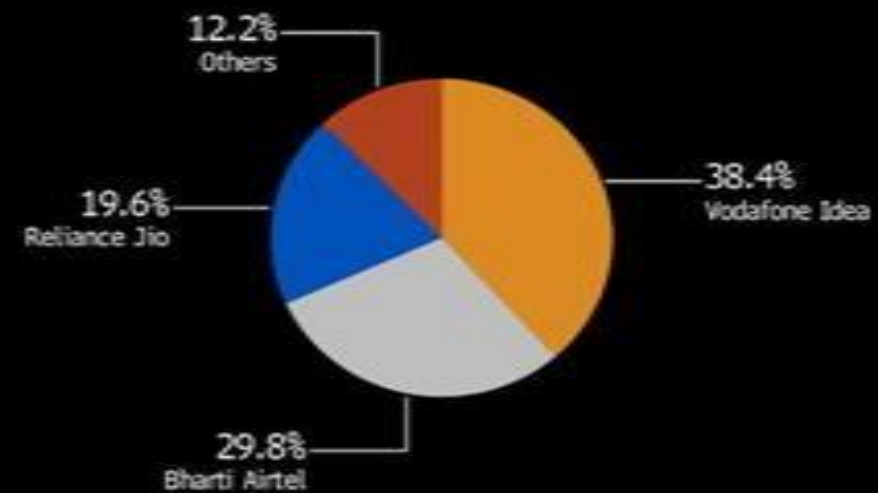

- While figures are as of the end of Xuly, Idea and Vodafone India formally completed their merger in hugust

(Source: Bloomberg, TRAI)

\section{Conclusion}


International Journal of Social Science and Economic Research

ISSN: 2455-8834

Volume:06, Issue:04 "April 2021"

The after effects of launch of Jio is like a tsunami, it completely swallowed/swallows anything that comes in front of it, just like that Jio swallowed every competitor, taking the life out of them, forcing them to move or exit or merge. Data, data in this era is the new oil. Ancient civilizations prospered when there was a river in the places they dwell, the modern era of civilization prospers when there is information available in abundance. As rightly said in a speech by Mr. Mukesh Ambani, availability of information will lead to India out of poverty, out of its misery thus, it is like oil. With the increase in the data consumption and every human being now relying and getting addicted to internet, Jio has created a perfect opportunity for itself. By enticing free calls for the end users and then tempting the users for free data in the beginning and now cheap data, once the habit is formed, itwouldn'tbedifficultforthemto retaintheir large directory of subscribers.

Jio has already announced its future plans of creating huge libraries of 10 million songs, 6,000 movies and 60,000 video songs, 1 lakh episodes of TV shows in more than 10 languages with their online streaming platforms such as JioSaavn and JioCinema. We can derive that in the coming days there can be massive investment in technology driven sectors and entertainment sector with each and every Jio user having access to $4 \mathrm{G}$ data with as low as ₹50 per month and thus Jio is now unstoppable. It is a bull which has been now set free in the fields that is the telecom industry to offer anything they want (also what the customer wants) at the lowest possibleprices.

From all the findings and analysis, we can reach the shores of conclusion that after the launch of Reliance Jio, the economic structure of the market is still the same, but the level of competition has grown unexpectedly.

If Jio continues at this pace, it will completely redefine the telecom sector in India and a new post Jio era will be formed in the sector where anything and everything is possible.

\section{Observations}

\section{$\underline{\text { Introduction }}$}

- Indian Telecommunications Industry is growing at an exponential rate and is expected to be one of the leading growth drivers of the Indian economy in the coming years. Reliance Jio has revolutionized the industry and has completely changed the way the industry functioned.

- The most satisfying factor amongst all users of Jio was analyzed as network stability, better coverage and faster mobiledata speeds.

- Consumers were not satisfied with the Customer care that Jio offers, Jio should focus on improving the customer care services that it has tooffer. 


\section{International Journal of Social Science and Economic Research}

ISSN: $2455-8834$

Volume:06, Issue:04 "April 2021"

- The consumers believe that the performance of Jio impacts the price movements of Relianceshare.

- The consumers perceive that Jio has led to a digital transformation in the Indian TelecomIndustry.

- Out of the total users of Jio, maximum number of users of Jio fall in the age gap of 15 to 20, Jio should focus on this age gap as this is the age when teenagers tend to spend more on entertainment andfeatures.

- Reliance Jio should now focus more on the rural areas of the country, with the literacy levels improving and the need for advancement arising in rural areas, it is a perfect opportunity for them as more and more people adapt to $4 \mathrm{G}$ and use more and more of data.

\section{Strategies Adopted by Competitors}

- Most of the competitors took the way of mergers and acquisition while some went bankrupt and were forced to exit. Competitors had to change their strategies completely and adopt new ones to survive in the market after Jio launched its services. Many competitors have now shut down operations or sold their assets due to the increased competition with only 3 major stakeholders left in theindustry.

- With the launch of Jio of companies witnessed a decline in their revenues to levels as low as $-300 \%$ per year.

- With greater network coverage and internet packages, at cheap rates, the consumers should try and experience the mega fish in the market that is Jio

- The average Jio user tends to spend 386 rupees per month while an Airtel user tends to spend on an average of ₹500 per month and Vodafone-Idea user spends ₹444 per month, with Jio being the cheapest, it has an upper hand over theindustry.

\section{Effect of Reliance Jio on Consumers}

Consumers have been the absolute winners after the entry of Reliance Jio with tariffs rates hitting rock bottom and data consumption increasing multi-fold. The aggressive strategies by Jio have made its subscribers and the general public believe to an extend that the customer is still the 'King of the market. Today, people from all walks of life living in the country has access to highspeed data, thanks to Reliance Jio's state of art 4G VoLTE technology. At cheaper and affordable rates, Jio's subscribers today has access to high-definition voice calling facilities and internet at faster speeds.

Due to the aggressive strategies enforced by Jio, all other major players in the market had to wake up to face the harsh reality that customers have a better option the other side at 
International Journal of Social Science and Economic Research

ISSN: 2455-8834

Volume:06, Issue:04 "April 2021"

aggressively competitive rates. Jio has been the torch bearer and the wake-up alarm to the typical Indian cellular subscribers. Customers realized that they can avail world class state of art data and voice facilities at their disposal at affordable prices.

The highly dynamic Indian economy, who at present is the largest consumer of mobile data, needs more players like Reliance Jio in all sectors that produces goods or provides services for the common people to keep the competition rolling, so that the consumers can witness and realize themselves that they can avail world's best services at affordable rates thereby each and everyone being accessible leading to the development of themselves.

\section{References}

Analytica, O. (2017). Oxford Analytica. Retrieved from https://www.oxan.com/: https://dailybrief.oxan.com/Analysis/DB254467/Reliance-could-end-up-with-digitalmonopoly-in-India

Chandergupta, A. (2018, April 6). The Economic Times. Retrieved from https://economictimes.indiatimes.com/: https://economictimes.indiatimes.com/tech/internet/jios-entry-led-to-10-billion-annualsavings-for-india-report/articleshow/63637786.cms

Gupta, D. (2017, February 27). India Today. Retrieved from www.indiatoday.in: https://www.indiatoday.in/technology/features/story/jio-effect-5-reasons-why-indiantelecom-industry-will-never-be-same-again-962875-2017-02-27

Haq, N. (2018, June). ResearchGate. Retrieved from www.researchgate.net: https://www.researchgate.net/publication/338829654_IMPACT_OF_RELIANCE_JIO_O N_FINANCIAL_PERFORMANCE_OF_KEY_PLAYERS_OF_TELECOM_INDUSTR $\mathrm{Y}$

Multiple. (n.d.). Wikipedia. Retrieved from en.wikipedia.org: https://en.wikipedia.org/wiki/Jio

Srivastava, A. (2017, September 5). LinkedIn. Retrieved from www.linkedin.com: https://www.linkedin.com/pulse/effect-jio-indian-telecom-industry-arpit-srivastava/

TRAI, T. R. (2021, January 21). Telecom Regulatory Authority of India. Retrieved from https://trai.gov.in/: https://trai.gov.in/sites/default/files/QPIR_21012021_0.pdf 